\title{
The effect of crystallinity and aging enthalpy on the mechanical properties of gelatin films
}

\author{
Chi-An Dai ${ }^{\text {a,*, Ming-Wei Liu }}{ }^{\mathrm{b}}$ \\ ${ }^{a}$ Department of Chemical Engineering and Institute of Polymer Science and Engineering, National Taiwan University, Taipei 106, Taiwan \\ ${ }^{\mathrm{b}}$ Taiwan Adventist Hospital, Taipei 105, Taiwan \\ Received 8 July 2005; received in revised form 30 September 2005; accepted 15 October 2005
}

\begin{abstract}
In this study the mechanical properties of gelatin films were evaluated for gelatin with varying amounts of structural gelatin (crystallinity) and aging enthalpy, which results from drying gelatin solutions under different conditions. The mechanical properties of a gelatin film were measured by the uniaxial tensile testing and the optical microscopy of the fractured films. Differential scanning calorimetry was used to measure crystallinity, and aging enthalpy was obtained from the thermogramic peak area of the corresponding transition. Gelatin films with crystallinity of less than $5 \mathrm{~J} / \mathrm{g}$ failed predominantly by brittle cracking fracture regardless of its aging enthalpy. However, for gelatin films with crystallinity of around $10 \mathrm{~J} / \mathrm{g}$, shear yielding was the dominant deformation mechanism for small aging enthalpy $(<3 \mathrm{~J} / \mathrm{g})$ while samples with larger aging enthalpy deformed by brittle cracking. For gelatin films with the largest crystallinity ( $>15 \mathrm{~J} / \mathrm{g})$, deformation was caused predominantly by shear yielding irrespective of the aging enthalpy. A fracture mechanism map based on its crystallinity and aging enthalpy for gelatin films was constructed.
\end{abstract}

(C) 2006 Elsevier B.V. All rights reserved.

Keywords: Physical aging; Brittle cracking fracture; Shear banding fracture; Gelatin films

\section{Introduction}

Gelatin is the partially renatured collagen, which consists of triple helical superstructure of extended polypeptide chains $[1,2]$. It has been widely used as binder or coating materials in the pharmaceutical, biomedical and photographic industries [3-5]. The mechanical and fracture behaviors of gelatin are therefore issues of technological importance, with impact on material composition, processing, and final performance of end products [6-11]. In order to determine the strength and endurance of gelatin, it is necessary to understand the microscopic deformation and fracture mechanisms of the gelatin.

To produce gelatin films, a coating process followed by a drying process of gelatin solutions is often employed. It is well known that during the drying process, gelatin chains may re-associate with each other to form partially renatured collagen-like structures as the solution is cooled below its coilhelix transition temperature [12]. The formation of renatured

\footnotetext{
* Corresponding author.

E-mail address: polymer@ntu.edu.tw (C.-A. Dai).
}

triple helix structure and its melting behavior have been found to be very similar to the crystallization phenomena in synthetic polymers $[13,14]$. As the solution is further cooled below its glass transition temperature, the glassy amorphous gelatin may also undergo a secondary enthalpic relaxation process often known as physical aging [15]. Marshall and Petrie conducted the aging study of gelatin films by annealing them below their glass transition temperature and found the aging kinetics of gelatin films is also similar to that of synthetic polymers [15].

However, gelatin is a unique biopolymer since it is known for its high humidity sensitivity that water serves mainly as a plasticizer in it. The glass transition temperature $\left(T_{\mathrm{g}}\right)$ increases from the ambient temperature to around $90-100{ }^{\circ} \mathrm{C}$ when the relative humidity of the environment decreases from $80 \%$ to $15 \%[5,15]$. With the glass transition temperature in the range of $50-60^{\circ} \mathrm{C}$, aging of a gelatin film is therefore expected even at room temperature. The process of physical aging is manifested by the change of thermal and mechanical properties including specific volume, enthalpy, modulus, loss tangent or refractive index for many synthetic polymers $[15,16]$. For biological materials like gelatin, reconstructed collagen, as well as wool, similar effects 


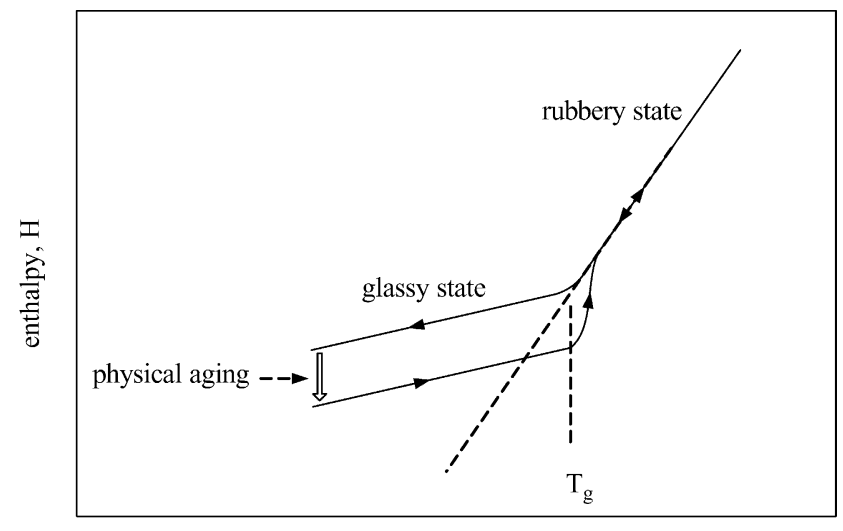

(a)

temperature

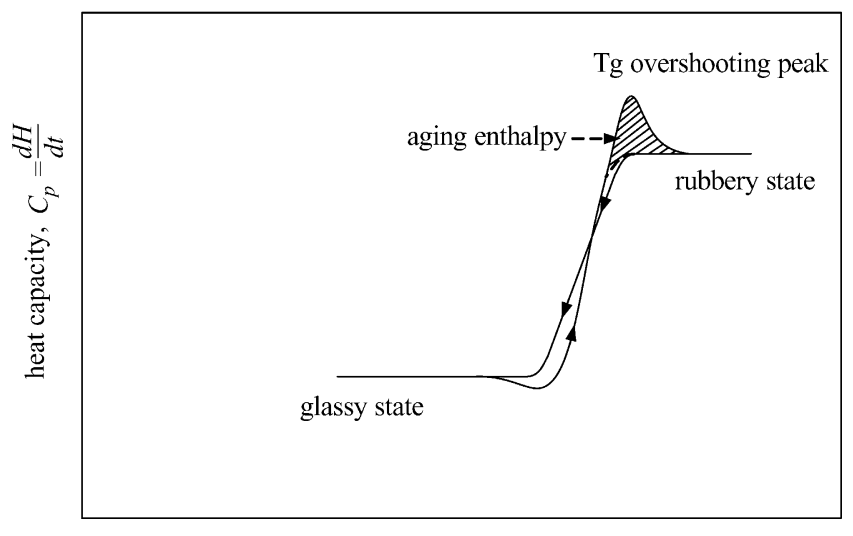

(b)

temperature

Fig. 1. Schematic illustrations of (a) enthalpy change and (b) heat capacity change for an amorphous glass undergoing physical aging process.

were also observed [16]. The effect of physical aging can be best demonstrated by differential scanning calorimetry (DSC) measurements, which are illustrated in Fig. 1 [17-19]. When a polymer is cooled and reheated near its $T_{\mathrm{g}}$, a hysteresis in its enthalpy is observed as shown in Fig. 1(a). The enthalpy of polymer glass decreases toward its equilibrium value as it is aged below its $T_{\mathrm{g}}$. The highly relaxed material does not reach the equilibrium state during reheating through $T_{\mathrm{g}}$ until a relatively high temperature as shown in Fig. 1(b). A classical $T_{\mathrm{g}}$ overshooting peak due to the aging process is accordingly demonstrated in the DSC measurement. Therefore, the area underneath this endothermic peak at the $T_{\mathrm{g}}$ can be used to quantify the extent of the enthalpy relaxation.

Recently, Bigi et al. [20,21] studied the effect of renaturation level of gelatin on the mechanical properties of uncrosslinked and crosslinked gelatin films. However, the combination effect of crystallinity and aging enthalpy on the mechanical properties, especially in the deformation and failure mechanism of gelatin, has not been fully investigated. In this study the mechanical and fracture properties of gelatin films with different crystallinity and physical aging are evaluated using a uniaxial tensile tester and optical microscopy for fracture morphology evaluation. The combination of these techniques allows us to establish a relationship between the thermal properties and the mechanical properties and the failure mechanisms of gelatin films.

\section{Experimental details}

\subsection{Sample preparation and DSC measurement}

The bovine gelatin powder was purchased from Showa Chemical Company of Japan. The gelatin powder was added to deionized water followed by heating the swollen powder/water mixture to $60{ }^{\circ} \mathrm{C}$ for $30 \mathrm{~min}$ to make a $10 \mathrm{wt} . \%$ homogeneous solution. Gelatin film of $\sim 15 \mu \mathrm{m}$ in thickness was prepared by using a doctor blades technique. In order to prepare free standing gelatin films, the gelatin solution was first coated onto the PET film surface and dried in a temperature and humidity controlled oven. The procedure of coating and drying of the gelatin layer follows Petri and co-worker [15]. During the drying process, some single stranded gelatin molecules undergo a coil-to-helix transition to form partially renatured structural gelatin. In addition, as gelatin films are dried below its glass transition temperature, physical aging of the gelatin films may also take place. The glass transition temperature, melting temperature, amount of structural gelatin and aging enthalpy were measured using a differential scanning calorimetry (Perkin-Elmer Pyris Diamond). The temperature and enthalpy scales were calibrated using standard samples of indium and zinc. To maintain the moisture content in the gelatin film during DSC measurement, a hermetic pan was used to seal each film sample of $\sim 10 \mathrm{mg}$ in a humidity controlled glove box at $50 \% \mathrm{RH}$ and $23^{\circ} \mathrm{C}$. Two consecutive temperature scans from 5 to $110^{\circ} \mathrm{C}$ with a scan rate of $10 \mathrm{~K} / \mathrm{min}$ were made for each gelatin film sample with different structural gelatin and aging enthalpy. Ultra-pure nitrogen was used as a purge gas at a rate of $20 \mathrm{ml} / \mathrm{min}$ during the measurement. The baseline subtraction was made to correct any heat capacity difference between the sample and the reference furnace.

\subsection{Tensile testing and fracture morphology observation}

Prior to mechanical measurements, all gelatin films are carefully peeled from the PET substrate and equilibrated in a humidity/temperature-controlled oven at $50 \%$ relative humidity (RH) and $23{ }^{\circ} \mathrm{C}$ for 1 day. The uniaxial stress-strain curves of the free-standing gelatin films were obtained using an Instron tensile tester with the humidity controlled glove box enclosing test samples. The uniaxial tensile testing is conducted with a fixed cross-head speed of $50 \mathrm{~mm} / \mathrm{min}$ at $23{ }^{\circ} \mathrm{C}$ and $50 \% \mathrm{RH}$. This procedure is consistent with the ASTM guidelines (D-638-89). The tensile moduli, break elongation and break strength were also obtained. After gelatin film samples were fractured, an optical microscope was used to examine the fracture morphology of the gelatin films. In order to obtain cross-sectional view of the fracture morphology, the fractured gelatin films were trimmed to produce smooth cross-sectional surface for optical microscopy observation. The gelatin film specimen was first embedded in epoxy followed by the curing of the epoxy for specimen fixation. An Isomet saw was then used to trim the cross-sectional surface of the gelatin films. 

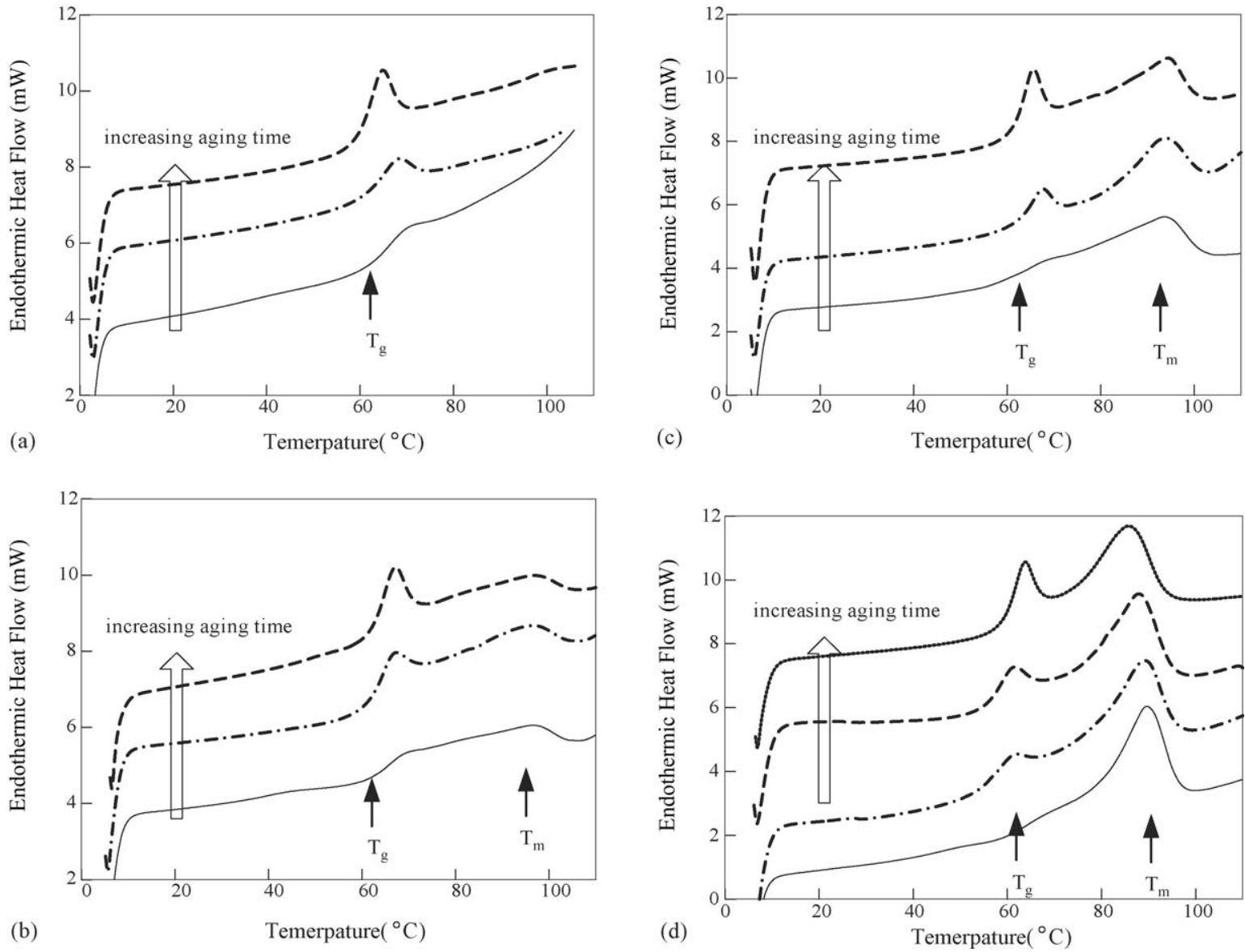

Fig. 2. DSC thermograms of a gelatin film prepared and drying at (a) $50{ }^{\circ} \mathrm{C}$ and $50 \% \mathrm{RH}$, (b) $35^{\circ} \mathrm{C}$ and $50 \% \mathrm{RH}$, (c) $30^{\circ} \mathrm{C}$ and $50 \% \mathrm{RH}$ and (d) $20^{\circ} \mathrm{C}$ and $50 \% \mathrm{RH}$.

Table 1

The notation of gelatin films used in this study and their corresponding structural gelatin content ( $\Delta H_{\text {crystal }}$ in units of $\mathrm{J} / \mathrm{g}$ ) and aging enthalpy ( $\Delta H_{\text {age }}$ in units of $\mathrm{J} / \mathrm{g}$ )

\begin{tabular}{|c|c|c|c|c|}
\hline & $\mathrm{COA} 0$ & & $\mathrm{C} 0 \mathrm{~A} 3$ & C0A5 \\
\hline \multicolumn{5}{|c|}{ Drying at $50^{\circ} \mathrm{C}$ and $50 \% \mathrm{RH}$} \\
\hline$\Delta H_{\text {crystal }}(\mathrm{J} / \mathrm{g})$ & & 0 & 0 & 0 \\
\hline \multirow{2}{*}{$\Delta H_{\text {age }}(\mathrm{J} / \mathrm{g})$} & & 0 & 3.6 & 5 \\
\hline & & $\mathrm{C} 4 \mathrm{~A} 0$ & $\mathrm{C} 4 \mathrm{~A} 2$ & C4A5 \\
\hline \multicolumn{5}{|c|}{ Drying at $35^{\circ} \mathrm{C}$ and $50 \% \mathrm{RH}$} \\
\hline \multirow{3}{*}{$\begin{array}{l}\Delta H_{\text {crystal }}(\mathrm{J} / \mathrm{g}) \\
\Delta H_{\text {age }}(\mathrm{J} / \mathrm{g})\end{array}$} & & 4.3 & 4.5 & 4.7 \\
\hline & & 0 & 2.3 & 5 \\
\hline & & C9A0 & C9A2 & C9A4 \\
\hline \multicolumn{5}{|c|}{ Drying at $30^{\circ} \mathrm{C}$ and $50 \% \mathrm{RH}$} \\
\hline \multirow{3}{*}{$\Delta H_{\text {age }}(\mathrm{J} / \mathrm{g})$} & & 10.5 & 8.9 & 9.3 \\
\hline & & 0 & 2.0 & 4.2 \\
\hline & $\mathrm{C} 15 \mathrm{~A} 0$ & $\mathrm{C} 15 \mathrm{~A} 2$ & $\mathrm{C} 15 \mathrm{~A} 3$ & $\mathrm{C} 15 \mathrm{~A} 4$ \\
\hline \multicolumn{5}{|c|}{ Drying at $20^{\circ} \mathrm{C}$ and $50 \% \mathrm{RH}$} \\
\hline$\Delta H_{\text {crystal }}(\mathrm{J} / \mathrm{g})$ & 16 & 15 & 16 & 15 \\
\hline$\Delta H_{\text {age }}(\mathrm{J} / \mathrm{g})$ & 0 & 1.6 & 2.7 & 4.5 \\
\hline
\end{tabular}

Samples with similar structural gelatin content were dried under the same temperature and humidity conditions for different period of time to obtain different aging enthalpy. Each value is the mean of five determinations from the DSC measurements. 


\section{Results and discussion}

\subsection{Correlation between thermal properties and fracture morphology}

The objective of the current study is to correlate the mechanical properties of gelatin films with their crystallinity and aging enthalpy measured from DSC. As shown in Fig. 2(a), a DSC thermogram for a gelatin film dried at $50{ }^{\circ} \mathrm{C}$ and $50 \%$ relative humidity (RH) for $12 \mathrm{~h}$ shows that the gelatin is completely amorphous with a $T_{\mathrm{g}}$ at around $60^{\circ} \mathrm{C}$. With increasing drying time at the same humidity and temperature, a $T_{\mathrm{g}}$ overshooting peak is observed to indicate an increase in aging enthalpy during the drying process. However, for gelatin films dried at a lower temperature of $35^{\circ} \mathrm{C}$ and $50 \% \mathrm{RH}$ for $12 \mathrm{~h}$, the DSC scan indicates that some structural order in gelatin with a melting
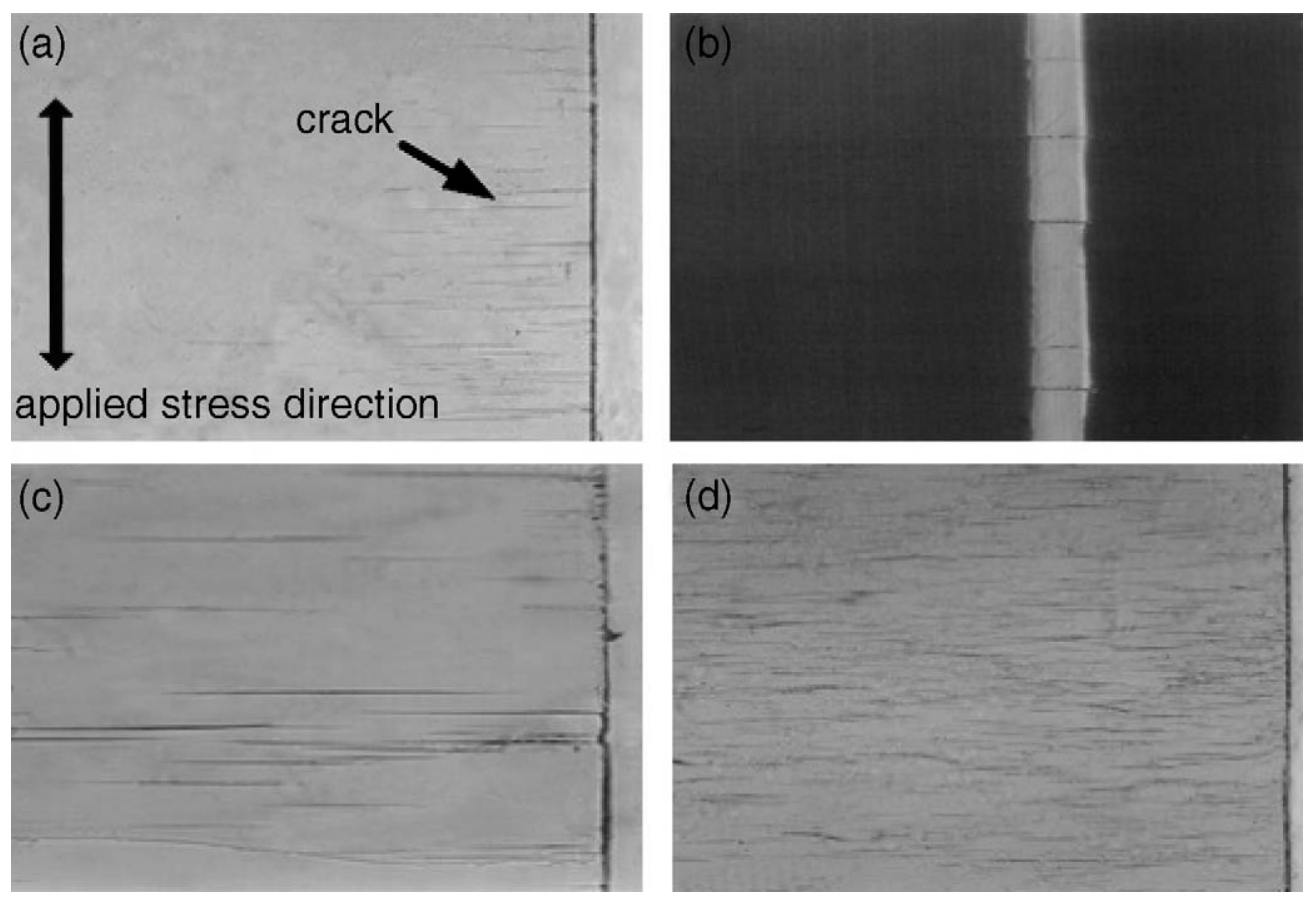

Fig. 3. (a) Optical micrographs of surface morphology of fractured C0A0 sample and (b) cross-sectional picture showing many cracks through-the-thickness direction of C0A0 sample. Optical micrographs of surface morphology of fractured (c) C0A3 and (d) C0A5 samples.
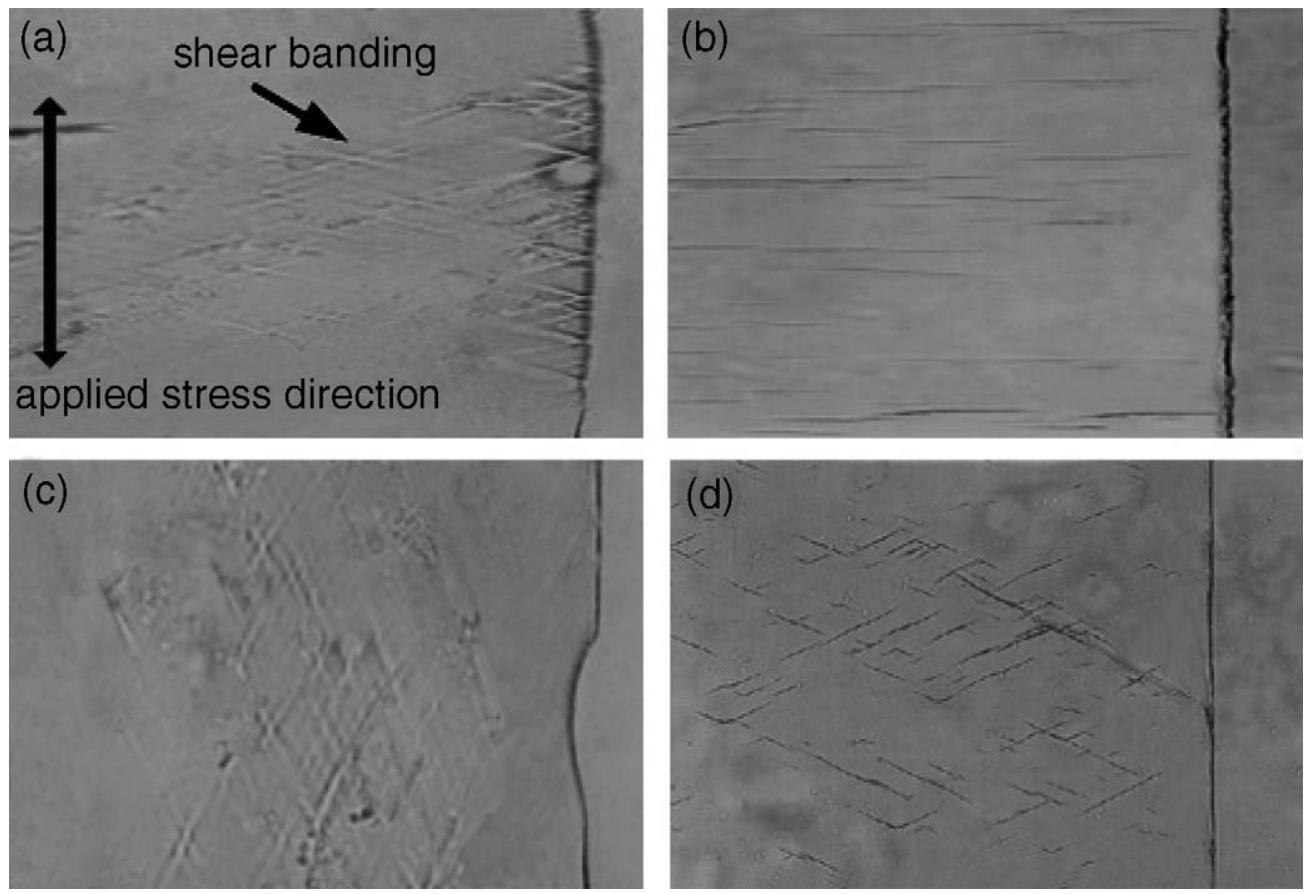

Fig. 4. Optical micrographs of surface morphology of fractured (a) C9A0, (b) C9A4, (c) C15A0 and (d) C15A4 samples. 
temperature $\left(T_{\mathrm{m}}\right)$ of around $95^{\circ} \mathrm{C}$ exists, as shown in Fig. 2(b). Similarly, with increasing drying time, an aging enthalpy peak around its $T_{\mathrm{g}}$ grows with drying time. For gelatin films with even higher crystallinity, the gelatin films were dried at lower temperatures of 30 and $20^{\circ} \mathrm{C}$ with its respective DSC thermograms shown in Fig. 2(c) and (d). Table 1 summarizes the notation of each film used in this study and its corresponding crystallinity and aging enthalpy.

Fig. 3(a) shows an optical micrograph of a $\mathrm{C} 0 \mathrm{~A} 0$ gelatin film after it has been fractured using a tensile test. The C0A0 sample is a gelatin film without any crystallinity $(C=0 \mathrm{~J} / \mathrm{g})$ and aging enthalpy $(A=0 \mathrm{~J} / \mathrm{g})$. Many small cracks were found on the surface of the gelatin coating. Since the fracture properties of most polymer glasses are linked to the stress-induced growth and breakdown of crazes, which are also planar crack-like defects, crazing is a possible deformation mechanism for gelatin [22]. One of the characteristic features of brittle crack/crazing fracture is that cracks/crazes propagate in a direction predominately perpendicular to the direction of the maximum principle tensile stress [22,23]. This feature is confirmed in Fig. 3(a). Note that in this study the applied tensile stress is always parallel to the film edge shown in all of the following optical micrographs. A cross-sectional picture of the gelatin film shows that many through-the-thickness cracks as well as some surface cracks exist in the gelatin film as shown in Fig. 3(b). Since a crack or craze, when it is not in tension at the time of observation, is closed and the instrumental resolution of optical microscope is limited, the exact brittle fracture mechanism (either by cracking or by crazing) cannot be distinguished. Similar cracking or crazing failure mechanisms are also observed for gelatin films of C0A3 and C0A5 as shown in Fig. 3(c) and (d), respectively. Therefore, it can be seen from the above figures, with increasing aging enthalpy, dense cracks/crazes on gelatin are found. For C4 sample series (C4A0, C4A2 and C4A5), brittle cracking/crazing fracture morphology was observed after tensile testing regardless of whether gelatins were physically aged or not.

Fig. 4(a) shows different deformation morphology for gelatin with higher structural order (C9A0 sample). Localized shear banding marks are found on the gelatin surface and the shear banding marks preferentially orient in a direction of roughly $45^{\circ}$ to the applied tensile stress. The deformation patterns are therefore generated in a direction parallel to the in-plane maximum shear stress based on the principle of stress transformation on thin films. This observation suggests that with increasing structural order, gelatin tends to deform and fail by shear. The same ductile failure mechanism was observed for C9A2 sample. However, for C9A4 sample, failure mechanism has shifted from shear to brittle cracking/crazing failure with cracks propagating in a direction perpendicular to the applied stress as shown in Fig. 4(b). Therefore, a transition from shear to cracking/crazing was observed for crystallinity $\sim 10 \mathrm{~J} / \mathrm{g}$. With even higher crystallinity, C15A0 sample again shows shear banding failure as shown in Fig. 4(c). However, Fig. 4(d) shows that a C15A4 sample deforms by shear cracking mechanism, which indicates that with increasing aging enthalpy a gelatin film fails by shear but the ductility of the film decreases.
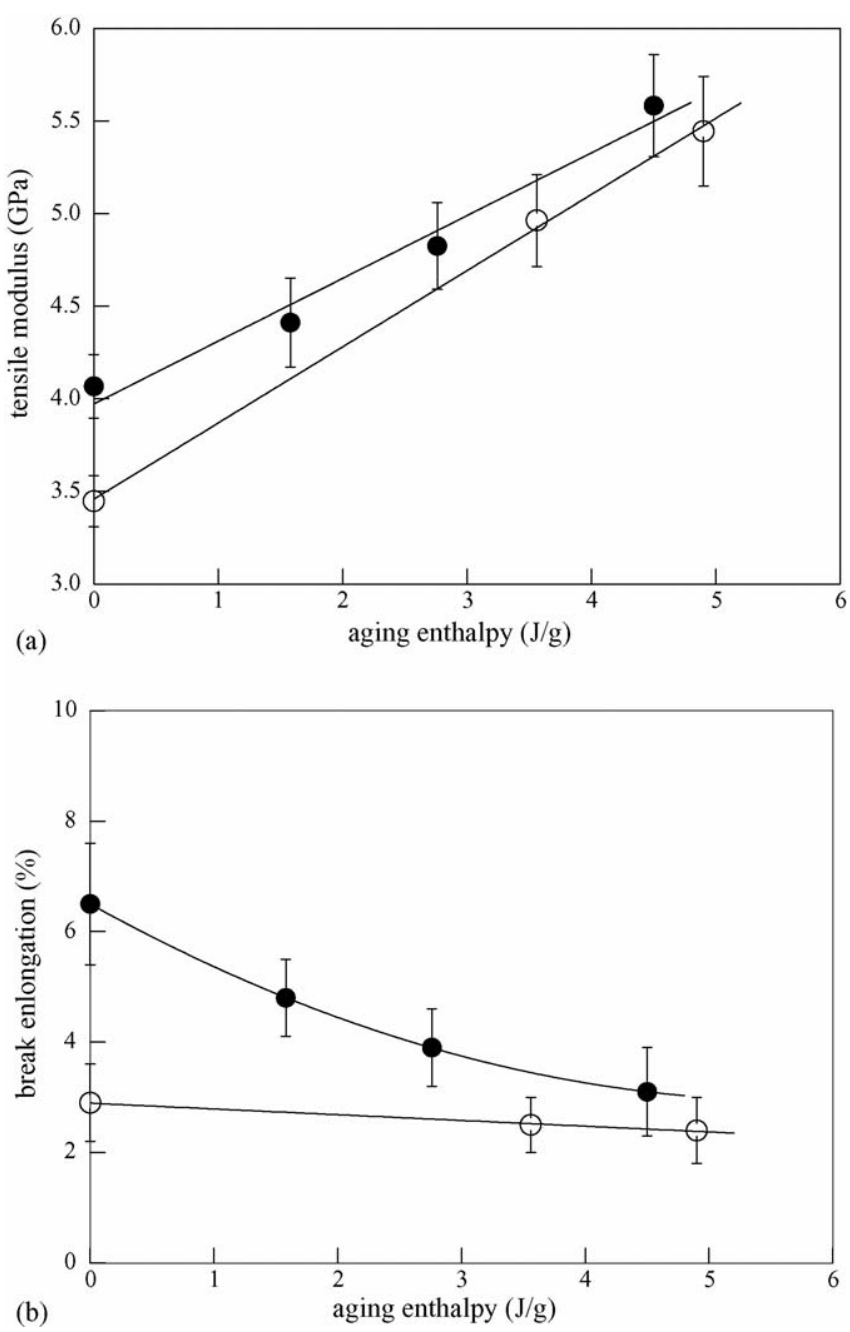

Fig. 5. (a) Tensile modulus and (b) break elongation of $\mathrm{C} 0(\bigcirc)$ and $\mathrm{C} 15($ sample series as a function of their aging enthalpy. Each value is the mean of five determinations and is plotted with its standard deviation.

The effect of crystallinity and aging enthalpy on the characteristics of stress-strain curve of gelatin films was investigated. The tensile modulus and break strain of gelatin films of $\mathrm{C} 0$ and C15 sample series are plotted as a function of aging enthalpy as shown in Fig. 5(a) and (b), respectively. For both $\mathrm{C} 0$ and C15 sample series the tensile modulus increases significantly with increasing aging enthalpy from 3 to $4 \mathrm{GPa}$ without any aging enthalpy to $5.5 \mathrm{GPa}$ with aging enthalpy of $\sim 5 \mathrm{~J} / \mathrm{g}$, an increase in the modulus of more than $50 \%$. The break elongation of amorphous gelatin films is less than $3 \%$ regardless of its aging enthalpy while that of gelatin with crystallinity of $15 \mathrm{~J} / \mathrm{g}$ decreases with increasing aging enthalpy and approaches to that of amorphous gelatin. Therefore the ductility of gelatin films increases with increasing crystallinity and decreases with increasing enthalpy. The change in mechanical properties due to physical aging has been known for many synthetic glassy amorphous polymers when they are annealed below their $T_{\mathrm{g}}$ 's [24-26]. Similar effects on the mechanical and fracture properties of gelatin films are observed. 

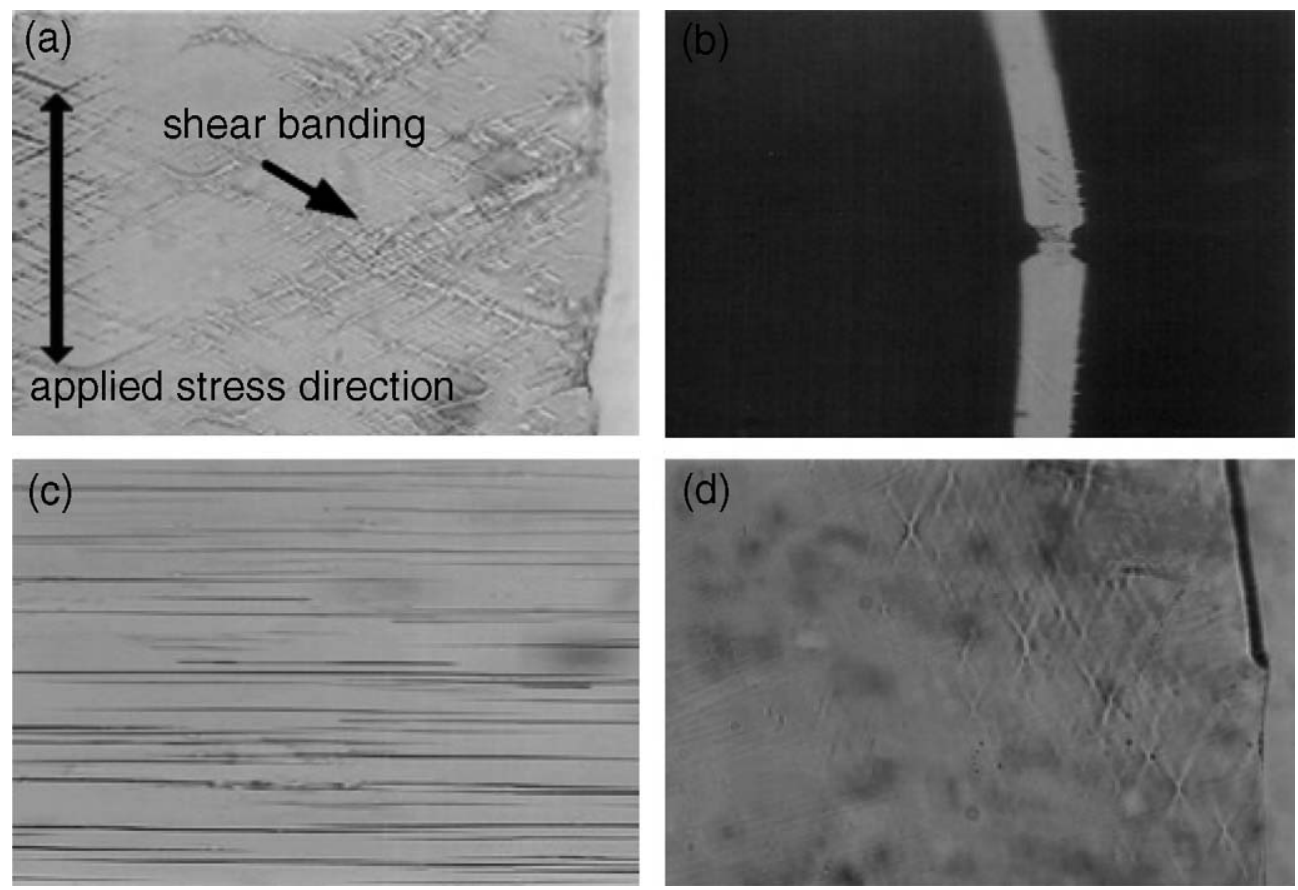

Fig. 6. (a) Optical micrographs of surface morphology of C4A5 sample conditioned and tested at $23{ }^{\circ} \mathrm{C}$ and $80 \%$ RH. Intense shear banding pattern is observed. (b) A cross-sectional picture showing necking behavior. (c) Optical micrographs of surface morphology of fractured C4A5 sample. (d) Fracture morphology of C4A5 after conditioning through the humidity cycle (50\% RH to $80 \% \mathrm{RH}$ to $15 \% \mathrm{RH}$ and $50 \% \mathrm{RH})$.

\subsection{Effect of humidity on mechanical properties}

A C4A5 sample, as mentioned previously, deforms by cracking/crazing at a condition of $23{ }^{\circ} \mathrm{C}$ and $50 \% \mathrm{RH}$. To investigate the effect of humidity on mechanical properties of gelatin films, a C4A5 sample is conditioned at $23^{\circ} \mathrm{C}$ and $80 \%$ RH for at least $24 \mathrm{~h}$. Tensile testing is subsequently conducted on the sample at the same temperature and humidity level. At $80 \%$ RH, gelatin's $T_{\mathrm{g}}$ is close to the room temperature such that tensile testing is conducted at a condition where gelatin films are in a rubbery state. Fig. 6(a) shows the surface morphology of a C4A5 sample conditioned and tested at $23{ }^{\circ} \mathrm{C}$ and $80 \% \mathrm{RH}$. Intense shear banding lines were observed on the gelatin surface. The orientation of shear banding patterns is parallel to the maximum shear stress, which is $45^{\circ}$ to the maximum applied tensile stress. Local shear necking was observed in a cross-sectional picture as shown in Fig. 6(b). The stress-strain curve of this gelatin coating shows substantial strain softening characteristics, which causes the inhomogeneous deformation of shear banding deformation mechanism. The average break strain of the gelatin was measured to be about $\sim 10 \%$.

\subsection{Deformation mechanism map}

From the above fracture morphology observations, a deformation mechanism map of gelatin films may be constructed as shown in Fig. 7 plotting the aging enthalpy as a function of crystallinity of gelatin films. At a testing environment of $23^{\circ} \mathrm{C}$ and $50 \% \mathrm{RH}$, gelatin without any aging enthalpy deforms by brittle cracking or crazing at low crystallinity and shear banding at higher crystallinity. The transition occurs around crystallinity of $\sim 5-10 \mathrm{~J} / \mathrm{g}$. This can be understood from many studies on synthetic polymers since it has been found that the competition between shear deformation and cracking/crazing is strongly dependent on the entanglement density of a polymer network. This has been confirmed in many polymer systems that a polymer with less entanglement density could deform by crazing while the high entanglement density counterpart deforms by shear [23]. Since during a drying process, gelatin forms a fringed micelle crystal structure [27] that also serves

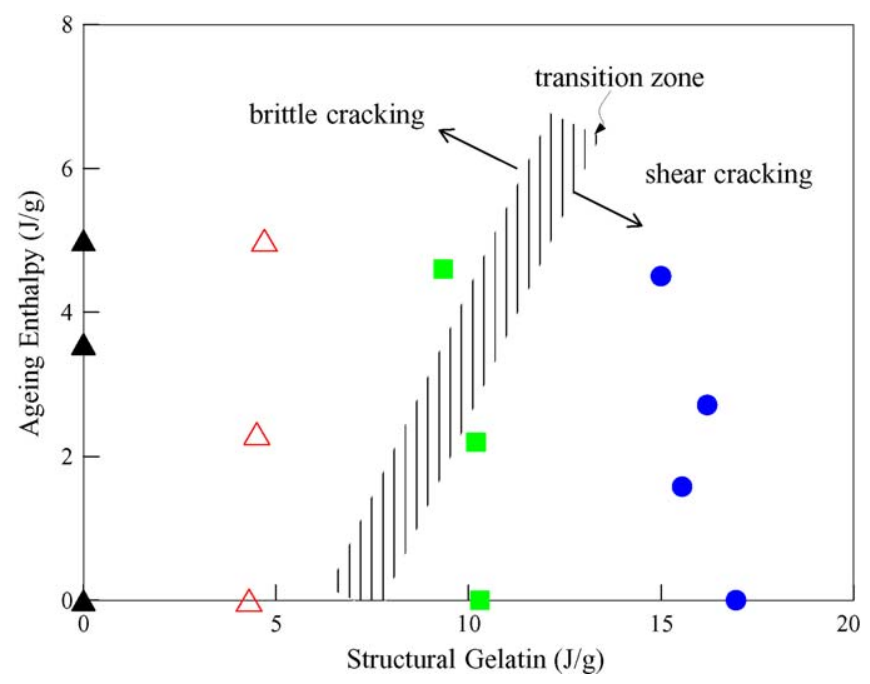

Fig. 7. Failure mechanism map for gelatin with different amount of structural order and aging enthalpy. The symbols used in this figure are gelatin samples dried at $50{ }^{\circ} \mathrm{C}$ and $50 \% \mathrm{RH}(\Delta)$, at $35^{\circ} \mathrm{C}$ and $50 \% \mathrm{RH}(\triangle)$, at $30^{\circ} \mathrm{C}$ and $50 \%$ $\mathrm{RH}(\boldsymbol{\square})$, and at $20^{\circ} \mathrm{C}$ and $50 \% \mathrm{RH}(\boldsymbol{O})$. 
as a physical cross-linking agent in the network, the mechanical integrity of gelatin is enhanced. Therefore, a transition from cracking/crazing to shear deformation is found for gelatin as the crystallinity increases. A close analogy is thus found between synthetic polymers and our biological gelatin material.

At an intermediate crystallinity $\left(\Delta H_{\text {crystal }} \sim 10 \mathrm{~J} / \mathrm{g}\right)$, there is a transition from shear to cracking failure. For many synthetic polymers, physical aging is known to raise the shear yielding stress but lesser effect on the crazing stress. Therefore it is not surprising that for gelatin with similar crystallinity, i.e. similar entanglement density, there is a transition from shear to cracking/crazing as its aging enthalpy increases. However, from the limited data presented here, the transition may be a straight line or a curved line. Typically, there may be a transition zone between crazing and shear yielding. Such a transition has been observed for many synthetic polymers [23]. At the highest crystallinity $\left(\Delta H_{\text {crystal }} \sim 15 \mathrm{~J} / \mathrm{g}\right)$, the entanglement density of gelatin is high enough that there is no transition from shear failure to cracking/crazing failure. However, at the highest crystallinity of $15 \mathrm{~J} / \mathrm{g}$, as the aging enthalpy increases all gelatins deform by shear, and the ductility of gelatin films decreases.

In order to test the criterion for the deformation transition from cracking/crazing to shear deformation, we conducted the following experiment. In order to erase its aging enthalpy without affecting its crystallinity, a C9A4 gelatin film was conditioned through a humidity circle, e.g. from $50 \% \mathrm{RH}$ to $80 \% \mathrm{RH}$ to $15 \% \mathrm{RH}$ and finally back to $50 \% \mathrm{RH}$ with each humidity step conditioned at least for $24 \mathrm{~h}$. At $23^{\circ} \mathrm{C}$ and $80 \% \mathrm{RH}$, gelatin's $T_{\mathrm{g}}$ is close to the room temperature such that its aging enthalpy is erased. Subsequently, DSC and tensile testing were conducted at $23{ }^{\circ} \mathrm{C}$ and $50 \%$ RH. Fig. 6(c) and (d) shows the fracture morphology of a C9A4 gelatin film before and after the humidity cycle, respectively. A C9A4 film, which deforms by brittle cracking/crazing previously deforms by shear banding after the humidity cycle. However, when a gelatin film with crystallinity less than $10 \mathrm{~J} / \mathrm{g}$, e.g. sample C4A5, is conditioned through a humidity cycle, the gelatin still deforms by cracking/crazing. Therefore, we verified the transition from cracking/crazing to shear at a crystallinity of $\sim 10 \mathrm{~J} / \mathrm{g}$ for gelatin.

\section{Conclusion}

We have investigated the effect of crystallinity and physical aging of gelatin films on their mechanical properties and failure mechanisms. The formation of crystallinity of gelatin depends strongly on the drying temperature at which gelatin films are coated. As a gelatin film is dried below its glass transition, the gelatin can undergo aging relaxation process, which depends on the drying temperature, humidity and the duration of drying. For gelatins without any aging enthalpy, there is a transition between cracking/crazing to shear banding failure at crystallinity of $\sim 5-10 \mathrm{~J} / \mathrm{g}$. For crystallinity $<5 \mathrm{~J} / \mathrm{g}$, the prevailing failure mechanism for gelatin is by cracking/crazing irrespective of aging enthalpy in gelatin. With increasing aging enthalpy, the ductility of a gelatin film decreases. For gelatin films with crystallinity $\sim 10 \mathrm{~J} / \mathrm{g}$, there is a transition from shear deformation to cracking/crazing failure for aging enthalpy $\sim 3 \mathrm{~J} / \mathrm{g}$. For gelatin films with crystallinity $\sim 15 \mathrm{~J} / \mathrm{g}$, the gelatin deforms predominantly by shear banding behavior, however the ductility of the gelatin decreases. The mechanical and fracture behaviors of gelatin are found to follow the generalization usually applied to synthetic amorphous and semicrystalline polymers.

\section{Acknowledgement}

This work was supported by the National Science Council of Taiwan under the contract number NSC94-2218-E-002-076 and NSC93-2120-M-002-010.

\section{References}

[1] G.N. Ramachandran, C. Ramakrishnan, in: G.N. Ramachandran, A.H. Reddi (Eds.), Biochemistry of Collagen, Plenum Press, New York, 1967.

[2] B. Brodsky, J.A.M. Ramshaw, Matrix Biol. 15 (1997) 545.

[3] R.G. Bosisio, T.W.C. Tang, P.B. Lamontagne, J. Appl. Polym. Sci. 25 (1980) 711-716.

[4] J.D. Kosmala, D.B. Henthorn, L. Brannon-Peppas, Biomaterials 21 (2000) 2019-2023.

[5] I. Rose, in: T.H. James (Ed.), The Theory of the Photographic Process, Macmillan, New York, 1977, pp. 51-67.

[6] A. Tanioka, K. Miyasaka, K. Ishikawa, Biopolymers 15 (1976) 1505.

[7] D. Achet, X.W. He, Polymer 36 (1995) 787.

[8] S.B. Ross-Murphy, Polymer 32 (1992) 3201.

[9] E. Esposito, R. Cortesi, C. Nastruzzi, Biomaterials 20 (1995) 2009.

[10] M. Usta, D.L. Piech, R.K. MacCrone, W.B. Hillig, Biomaterials 24 (2003) 165.

[11] G.A. Digenis, T.B. Gold, V.P. Shah, J. Pharm. Sci. 83 (1994) 915.

[12] S.E.B. Petrie, J. Polym. Sci. Part A-2 10 (1972) 1255.

[13] D.D. Macsuga, Biopolymers 11 (1972) 2521.

[14] W. Bouchard, W. Bremer, A. Keese (Eds.), J. Polym. Sci., Polym. Phys. 16 (1980) 1817

[15] A.S. Marshall, S.E.B. Petrie, J. Photogr. Sci. 28 (1980) 128.

[16] L.C.E. Struik, Physical Aging in Amorphous Polymer and Other Materials, Elsevier, Amsterdam, 1978, pp. 5-10.

[17] A.J. Kovacs, J.J. Aklonis, J.M.R. Hutchinson, A. R., J. Polym. Sci., Polym. Phys. 17 (1979) 1097.

[18] G.W. Sherer, Relaxation in Glass and Composites, Wiley-Interscience, 1986, p. 1.

[19] A.R. Berens, I.M. Hodge, Macromolecules 15 (1992) 756.

[20] A. Bigi, G. Cojazzi, S. Panzavolta, N. Roveri, K. Rubini, Biomaterials 22 (2001) 763.

[21] A. Bigi, S. Panzavolta, K. Rubini, Biomaterials 25 (2004) 5675.

[22] E.J. Kramer, in: H.H. Kausch (Ed.), Advances in Polymer Science, Springer-Verlag, New York, 1983, p. 5.

[23] E.J. Kramer, L.L. Berger, in: H.H. Kausch (Ed.), Advances in Polymer Science, Springer-Verlag, New York, 1989, p. 5.

[24] G.A. Adam, R.N. Gross, R.N. Haward, J. Mater. Sci. 10 (1975) 1582

[25] N. Nerheulpen-Heymans, J.C. Bauwens, J. Mater. Sci. 11 (1976) 1.

[26] M.S. Ali, R.P. Sheldon, J. Appl. Polym. Sci. 14 (1970) 2619.

[27] P. Godard, J.J. Biebuyck, M. Daumerie, H. Naveau, J.P. Mercier, J. Polym. Sci., Polym. Phys. Ed. 16 (1978) 1817. 